\title{
Novel triamcinolone acetonide-loaded liposomes topical formulation to prevent cystoid macular edema after femtosecond laser-assisted cataract surgery
}

\section{Nueva formulación tópica de liposomas cargados con acetónido de triamcinolona para prevenir el edema macular cistoide asociado a la cirugía de catarata asistida con láser de femtosegundo}

\author{
Jose Navarro-Partida1,2, Gerardo D. Jauregui-García1, Juan C. Altamirano-Vallejo ${ }^{1,2}$, Ricardo Acosta-González², \\ Alejandro González-De la Rosa ${ }^{1,2}$, Juan Armendáriz-Borunda1,3 and Arturo Santos, ,2,* \\ ${ }^{1}$ Tecnologico de Monterrey, Escuela de Medicina y Ciencias de la Salud, Campus Guadalajara, Zapopan; ${ }^{2}$ Centro de Retina Medica y Quirúrgica, \\ Centro Médico Puerta de Hierro, Zapopan; ${ }^{3}$ Instituto de Biología Molecular y Terapia Génica, Centro Universitario de Ciencias de la Salud, \\ Universidad de Guadalajara, Guadalajara. Jalisco, Mexico
}

\begin{abstract}
Aim: The aim of this study is to report the tolerability, safety and efficacy of a topical triamcinolone acetonide-loaded liposomes formulation (TA-LF) to prevent clinically significant macular edema (CSME) after femtosecond laser-assisted cataract surgery (FLACS). Methods: Fifty-five eyes of 32 patients who underwent FLACS were enrolled. Twenty-seven eyes were assigned to the TA group whereas twenty-eight eyes were assigned to the TA-LF group. In the TA group, eyes were exposed to a conventional topical formulation of triamcinolone acetonide $0.1 \%$ for 21 days postoperatively, whereas patients in the TA-LF group received a liposomal formulation containing $2 \mathrm{mg} / \mathrm{ml}$ of TA $(0.2 \%)$. A follow-up consisting on slit-lamp examination, visual acuity, contrast sensitivity, central foveal thickness (CFT) and total macular volume (TMV) (both measured by retinal optical coherence tomography) was performed. Study visits were scheduled at 1 day, 6 , and 12 weeks after surgery. Results: The incidence of CSME in the TA group at 6 weeks was 22.2\%, in contrast, the incidence of these finding in the TA-LF group was $0 \%$. A conventional steroid formulation (TA 0.1\%) was associated with an increased risk of CSME (OR, 9.44; 95\% Cl, 1.76 - 50.66; $P=0.027)$. Finally, no ocular or systemic adverse events were reported in any group. Conclusion: TAloaded liposomal formulation is effective for the prevention of CSME associated with FLACS, and it seems that its therapeutic activity could be superior to the activity of a conventional topical steroid formulation.
\end{abstract}

Key words: Liposomes. Triamcinolone acetonide. Macular edema. Femtosecond laser-assisted cataract surgery.

Correspondence:

*Arturo Santos

Ciencias de la Salud, Tecnológico de Monterrey, Campus

Guadalajara.Av.General Ramón Corona, 2514.Zapopan, Jalisco, Mexico

Date of reception: 08-05-2019

Date of acceptance: 06-05-2020 DOI: 10.24875/RMOE.M20000114
Available online: 01-09-2020 Rev Mex Oftalmol (Eng). 2020;94(5):173-182

www.rmo.com.mx 


\section{Resumen}

Objetivo: El objetivo de este estudio es informar la tolerabilidad, la seguridad y la eficacia de una nueva formulación de liposomas de uso tópico cargados con acetónido de triamcinolona (FL-AT), útil en la prevención del edema macular clínicamente significativo (EMCS) que ocurre después de la cirugía de catarata asistida con láser de femtosegundo (FLACS). Métodos: Se estudiaron 55 ojos de 32 pacientes a los que se realizó FLACS. Se asignaron 27 ojos al grupo de acetónido de triamcinolona (AT), mientras que 28 ojos fueron asignados al grupo de FL-AT. En el grupo de AT, los ojos se expusieron a una formulación tópica convencional de AT al $0.1 \%$ durante 21 días tras la cirugía, mientras que los pacientes en el grupo de FL-AT recibieron una formulación liposomal que contenía $2 \mathrm{mg} / \mathrm{ml}$ de $A T(0.2 \%)$. Se realizó un seguimiento clínico que comprendió: examen con lámpara de hendidura, agudeza visual, sensibilidad al contraste, grosor foveal central y volumen macular total. Las visitas del estudio se programaron los días 1 y 6 y al final de la semana 12 del periodo postoperatorio. Resultados: La incidencia de EMCS en el grupo de AT a las 6 semanas fue del 22.2\%, en contraste con el grupo de FL-AT, en el cual fue de $0 \%$. La formulación de esteroides convencionales (AT al $0.1 \%$ ) se asoció con un mayor riesgo de EMCS (OR: 9.44; IC del 95\%: 1.76-50.66; $p=0.027$ ). Finalmente, no se reportaron eventos adversos oculares ni sistémicos en ningún grupo. Conclusión: La FL-AT es eficaz para la prevención del EMCS asociado con FLACS, y parece que su actividad terapéutica es superior a la actividad de la formulación de esteroides tópicos convencionales.

Palabras clave: Liposomas. Acetónido de triamcinolona. Edema macular. Cirugía de catarata asistida con láser de femtosegundo.

\section{Introduction}

Nowadays, cataract remains the number one treatable cause of blindness and severe visual impairment worldwide 1 . Cataract surgery improves visual acuity in the majority of patients and is considered one of the most cost-effective of all healthcare interventions ${ }^{2}$. Femtosecond laser-assisted cataract surgery (FLACS) appears to improve outcomes and safety over conventional phacoemulsification, gaining popularity among cataract surgeons. In a recent study comparing FLACS and conventional phacoemulsification, both had comparable refractive and visual results. However, FLACS showed less phacoemulsification energy, postoperative anterior chamber inflammation and corneal endothelial cell loss ${ }^{3}$.

Current cataract surgery techniques significantly reduce postoperative complications. Nevertheless, pseudophakic cystoid macular edema (PCME) is still the most common cause of decreased central visual acuity (CVA) after successful cataract surgery. Clinical PCME is defined by symptomatic visual loss and its incidence ranges from $1.17-4.04 \% \%^{4}$. However, the occurrence of PCME, diagnosed by optical coherence tomography (OCT), can be as high as $10.9 \%$. Previous studies showed less anterior chamber flare and decreased central macular thickness with FLACS compared to conventional phacoemulsification ${ }^{6-8}$, nonetheless, PCME has been reported with FLACS. The reported prevalence of postoperative CME associated with FLACS is of around $0.8 \%{ }^{9}$, and it is comparable with previous published values for conventional phacoemulsification cataract surgery $(0.1 \% \text { to } 2.35 \%)^{10,11}$.
Clinically significant PCME commonly starts 4 to 12 weeks after surgery, with its highest incidence at 4 to 6 weeks. Patients with clinically significant PCME commonly experience an initial postoperative visual acuity improvement followed by a reduction of central vision. ${ }^{12}$ Known risk factors for PCME include diabetes mellitus ${ }^{4,13}$, YAG capsulotomy, uveitis ${ }^{4,14}$, use of topical prostaglandin analogs,${ }^{15,16}$ trauma, ${ }^{17}$ and intraoperative complications ${ }^{18,19}$.

PCME pathogenesis is complex and involves the production of prostaglandins (PGs), cytokines, and other factors released during surgical trauma that disrupt the blood-retinal barrier ${ }^{12}$. Therapeutic tools available for prophylaxis and treatment of PCME are based on the understanding of these factors and their pathways. The best prophylactic regimen for PCME has not been established, but corticosteroids and topical nonsteroidal anti-inflammatory drugs (NSAIDs), alone or combined have proven to be useful|20-23 and are extensively used as the first-line drugs ${ }^{24}$. A previous comprehensive study to evaluate PCME prevention after cataract surgery demonstrated that topical therapy with NSAIDs (bromfenac $0.09 \%$ ) or steroids (dexamethasone $0.1 \%$ ) alone, was related to a higher incidence of clinically significant PCME 12 weeks postoperatively (incidence of $3.6 \%$ and $5.1 \%$, respectively) compared to combined therapy (incidence of $1.5 \%)^{25}$.

The higher efficacy of the topical combination could be related to the different mechanisms of action of steroids and NSAIDs. Corticosteroids block the synthesis of leukotrienes and prostaglandins (PGs) and reduce macrophage and neutrophil migration, along with 
capillary permeability and vasodilation. On the other hand, NSAIDs inhibit cyclooxygenase enzymes, restricting the synthesis of PGs and thromboxanes, as well as decreasing vasodilatation and preventing disruption of the blood-ocular barrier ${ }^{24}$. The reduced therapeutic activity of topical corticosteroids could be explained by the limited concentration of the drug reaching the posterior segment of the eye due to the presence of both the ocular and the blood-retinal barriers. Therefore, intravitreal injections of steroids reach suitable intraocular concentrations, avoiding the ocular barriers ${ }^{26}$.

Refractory and chronic PCME can be successfully managed with intravitreal corticosteroids. Intravitreal triamcinolone acetonide (IVTA) effectively improves visual acuity and reduces macular thickness ${ }^{27-30}$. However, IVTA is associated with potentially severe complications such as increased intraocular pressure $^{27,30}$, endophthalmitis, lens injury, retinal detachment ${ }^{31-33}$, cataract formation or progression, and noninfectious endophthalmitis ${ }^{34-36}$.

There is a need for alternative drug delivery strategies for PCME that minimize the risks of intravitreal injections but are as effective as IVTA. Recently, we reported a topical triamcinolone acetonide-loaded liposomes formulation (TA-LF) that effectively delivers triamcinolone into the vitreous and the retina of rabbits ${ }^{37}$, and its biological and therapeutic activity was also confirmed in patients with refractory $\mathrm{PCME}^{38}$, showing that the use of this formulation induced an improvement of best-corrected visual acuity (BCVA) and CFT (central foveal thickness). Also, we recently published the comparison of TA-LF with NSAIDs ${ }^{39}$. In this study, we proved that TA-LF correlates with better contrast sensitivity outcomes compared to combined therapy (prednisolone $1 \%$ and nepafenac $0.1 \%$ ) after FLACS. Interestingly, no difference was observed in the incidence of clinically significant macular edema (CSME) between groups ${ }^{39}$. In the current study, we decided to compare the TA-LF formulation with ophthalmic suspensions of conventional steroids, to report the evaluation of tolerability, safety, and efficacy of topical TA-LF for PCME prevention following FLACS.

\section{Patients and methods}

\section{Study design}

This was a single-center (Centro de Retina Medica y Quirurgica S.C., Guadalajara, Mexico), two-arm, double-blind, randomized, prospective study. The study adheres to the tenets of the Declaration of Helsinki and the hospital Ethics Committee approvals, and local and federal regulatory agreements (COFEPRIS 173300410A0035/2017). All patients who underwent the procedure and entered the study signed an informed consent, and all data were collected prospectively on standardized case report forms.

\section{Patients}

Patients who were 21 years-old or older who required FLACS and posterior chamber lens implantation in at least 1 eye were enrolled. Demographic data and a baseline clinical exam that included CFT measurement by optical coherence tomography, were collected from 1 to 14 days before surgery. Exclusion criteria included use of topical steroids or topical NSAIDs 1 month prior to the study, placement of a steroid ocular implant 12 months before study enrollment, use of intraocular corticosteroids or anti-angiogenic drugs 3 months prior to the study, traumatic cataract or nuclear opacity or lens color greater than grade 3 (based on lens opacities classification system III (LOCS III)). We also excluded patients with ocular diseases that prevented an adequate examination of the fundus, any ocular disease that could be responsible for decreased visual acuity (diabetic retinopathy, vascular occlusion, macular degeneration), ocular hypertension, glaucoma, unstable systemic disease including systemic hypertension, diabetes mellitus, previous eye disease resulting in a medical history of CME. Subjects with previous cerebrovascular accident (CVA), or myocardial infarction (MI) were also excluded. Only patients who underwent uncomplicated cataract surgery were included.

\section{SURGICAL TECHNIQUES AND ASSIGNED THERAPY}

All patients received the same preoperative and intraoperative treatment for both eyes. All surgeries were performed under topical anesthesia using tetracaine hydrochloride 5\% (Ponti Ofteno, Sophia Labs., Zapopan, Mex.). To maintain pupil dilation during the entire surgery, tropicamide $0.8 \%$ and phenylephrine hydrochloride 5\% (T-P Ofteno, Sophia Labs., Zapopan, Mex.) were used. Patients underwent FLACS, received the laser portion of the procedure first. The LenSX laser system (Alcon, Inc., USA) was used to perform anterior capsulotomy, lens fragmentation and then corneal incisions (temporal main incision and 2 paracentesis side ports), in that sequence. A suction ring was first applied. A circular capsulotomy was created with the energy set at $9 \mu \mathrm{J}$. The diameter of the capsulotomy was $5.0 \mathrm{~mm}$. A combined circular (2 circles, diameter of 2.0 
$\mathrm{mm}$ and $2.8 \mathrm{~mm}$ ) and 4-cut cross-shaped pattern (diameter of $8.0 \mathrm{~mm}$ ) was used for lens fragmentation with pulse energy at $10 \mu \mathrm{J}$. A femtosecond laser was used to create two paracentesis ports and a clear corneal incision. The width of the main port corneal incision was of $2.2 \mathrm{~mm}$ and $1.0 \mathrm{~mm}$ for each of the 2 side ports. Main port was positioned at $210^{\circ}$ in the right eye and $30^{\circ}$ in the left eye. Side ports were at $95^{\circ}$ and $275^{\circ}$ in the right eye, and at $100^{\circ}$ and $280^{\circ}$ in the left eye.

After femtosecond laser treatment, patients were transferred to the operating room for phacoemulsification. After sedation, corneal incisions were opened and the separated anterior capsule was removed with forceps. All other steps were similar to conventional phacoemulsification. All patients received the Alcon AcrySof ${ }^{\circledR} I Q$ PanOptix ${ }^{\top M}$ Presbyopia-Correcting Intraocular Lens.

After surgery, patients were randomly assigned to 1 of 2 treatment groups. Patients in the TA group received triamcinolone acetonide $0.1 \%$ eyedrops commercially available in Mexico (Softram, Laboratorios Grin, S.A. de C.V; 03-04-2008 / 087M2008 SSA / IPP: DEAR 05330060101527/R-2008) four times per day for 21 days postoperatively, whereas patients in the TA-LF groups received a liposomal formulation containing $2 \mathrm{mg} / \mathrm{ml}$ of TA $(0.2 \%)$ four times per day for 21 days postoperatively. No other ocular corticosteroids or NSAIDs were allowed during the course of the study. All patients received postoperative gatifloxacin $0.3 \%$ four times per day for 14 days (Zymar, Allergan, Irvine, CA, USA).

\section{Efficacy assessment}

In order to evaluate the therapeutic efficacy of TA-LF $0.2 \%$ compared to TA $0.1 \%$, a follow-up including visual acuity, contrast sensitivity, central foveal thickness (CFT) and total macular volume (TMV) was performed. BCVA was measured using an ETDRS chart at $4 \mathrm{~m}$ and the measured visual acuity was expressed as the logarithm of the minimal angle of resolution (logMar). Contrast sensitivity (CS) was evaluated by the Pelli-Robson contrast sensitivity test. The values of logarithmic contrast sensitivity (1/contrast), as well as visual acuity values, were recorded at each study visit. CFT and TMV analysis, was performed with a retinal optical coherence tomography (OCT) (Cirrus OCT Carl Zeiss, Meditec, Dublin, CA). Study visits were scheduled on day 1 , and weeks 6 and 12 after surgery. Additionally, ocular surface staining with fluorescein, IOP, and slitlamp anterior and posterior segment evaluation where performed at each visit with the purpose of identifying ocular adverse events.

The occurrence of cystoid macular edema (CME) and clinically significant macular edema (CSME) was explored at weeks 6 and 12. Cystoid macular edema was defined as an increase in central subfield mean macular thickness of $10 \%$ or more over baseline, with cystic changes on OCT. Cystoid changes and other retinal disorders were identified by 2 independent and masked retina specialists. CSME was defined as CME with less than a 0.2 logMAR BCVA improvement compared with preoperative baseline ${ }^{25}$.

\section{Safety assessment}

Tolerability was assessed through collection and summary of ocular and non-ocular adverse events (AEs), serious AEs (SAEs), ocular assessments and vital signs, whether volunteered by the enrolled patients, discovered by study site personnel during questioning, or other means. Subjects were withdrawn if they showed any evidence of poor tolerability or any adverse event, such as corneal ulcers, corneal opacities, epithelial defects, anterior chamber inflammation (cell/flare) or conjunctival and/or episcleral injection-related to the use of this topical formulation. AEs were coded using the standard codes terms for the event based on the Medical Dictionary for Regulatory Activities Terminology (MedDRA) version 18.1.

\section{RESCUe tREATMENT}

Rescue treatment with a topical combination of prednisolone $1 \% 4$ times daily and nepafenac $0.1 \% 3$ times daily for 4 weeks was considered when patients developed CSME during the course of the study. If CSME resolved within these 4 weeks, nepafenac was stopped and prednisolone eye drops were tapered 1 drop per day every following week. If CSME persisted after 4 weeks of topical treatment, patients received 1 intravitreal injection of $4 \mathrm{mg}$ of preservative-free TA. IOP-lowering drugs were considered when measured IOP was $\geq 22 \mathrm{mmHg}$ or with a difference $>4 \mathrm{mmHg}$ compared to the contralateral eye.

\section{Preparation of liposomal formulation}

OPKO Health, Inc. (Guadalajara, Jalisco, Mexico) provided a triamcinolone acetonide-loaded liposomes formulation (TA-LF). Preparation of TA-LF was carried out as previously described ${ }^{37}$. Briefly, self-forming, 
thermodynamically stable TA-loaded liposomes (QuSomes ${ }^{\circledR}$ ) were generated spontaneously upon adding polyethylene glycol glyceryl dimyristate (PEG-12) to an aqueous solution containing triamcinolone acetonide (TA). The composition of the TA-LF is described in table 1. Final TA concentration in the resultant dispersion was $2 \mathrm{mg} / \mathrm{ml}(0.2 \%)$.

\section{Statistical analysis}

Data were analyzed using the SPSS 22.0 software (IBM SPSS Statistics for Macintosh, Version 22.0. Armonk, NY, USA: IBM Corp.). Quantitative variables were described using mean and standard deviation. Qualitative variables were described using frequencies and percentages. We performed a Wilcoxon signedrank test and Mann-Whitney $U$ test for the analysis of age, BCVA, CS, CFT, TMV and IOP in dependent and independent samples, respectively. For the analysis of gender and study eye, a Fisher exact test was performed. Correlation between the variables was measured by Pearson's $r$ to subsequently calculate the coefficient of determination $\left(r^{2}\right)$. Significance was defined as a $P$ value less than 0.05 .

\section{Results}

Fifty-five eyes of 32 patients were enrolled. Twenty-nine of the 55 study eyes were right and 26 were left. The male: female ratio for the enrolled patients was 15:17. Twenty-seven eyes were assigned to the TA group, whereas twenty-eight eyes were assigned to the TA-LF group. Only 21 eyes from the TA group completed 12 weeks of follow-up, because six patients required rescue treatment at week 6 for CSME. All patients of the TA-LF group finished the follow-up. Figure 1 shows a flow diagram with the number of eyes randomized and analyzed. The patient's clinical characteristics in the TA and TA-LF groups are summarized in Table 2.

Regarding tolerability and safety outcomes, we observed that the TA-LF was well tolerated during the study period. No ocular (increased intraocular pressure, ocular surface abnormalities) or systemic adverse events were reported. None of the patients showed a significant IOP increase. In fact, a significant IOP reduction was observed in the TA and TA-LF groups. IOP levels decreased from $15.11 \pm 3.25$ to $12.88 \pm 3.02$ at week 6 in the TA group, whereas IOP levels decreased from $15.71 \pm 2.20$ to $12.89 \pm 2.69$ at week 6 in the TALF group (Table 3 ). None of the patients required IOP-lowering drugs. None of the patients showed signs
Table 1. Triamcinolone acetonide loaded liposomes formulation (TA-LF) composition

\begin{tabular}{|l|c|}
\hline Reagent & Volume \\
\hline Triamcinolone acetonide & $2.0 \mathrm{mg}$ \\
\hline Kolliphor HS 15 & $50 \mathrm{mg}$ \\
\hline PEG-12 glyceryl dimyristate & $100 \mathrm{mg}$ \\
\hline Ethyl alcohol & $14 \mu \mathrm{L}$ \\
\hline Citric acid anhydrous & $0.8 \mathrm{mg}$ \\
\hline Sodium citrate dihydrate & $4.675 \mathrm{mg}$ \\
\hline Benzalkonium chloride & $0.1 \mathrm{mg}$ \\
\hline Grade 2 purified water & $0.5 .1 .0 \mathrm{ml}$ \\
\hline
\end{tabular}

Table 2. Clinical characteristics of the groups

\begin{tabular}{|c|c|c|c|}
\hline & TA & TA-LF & P-value \\
\cline { 2 - 3 } & $\mathrm{n}=27$ & $\mathrm{n}=28$ & \\
\cline { 1 - 3 } Age & $57.25 \pm 7.0$ & $58.39 \pm 5.7$ & 0.5099 \\
\hline $\begin{array}{c}\text { Gender } \\
\text { F }\end{array}$ & $15(0.55)$ & $18(0.64)$ & 0.5088 \\
\hline $\mathrm{M}$ & $12(0.45)$ & $10(0.36)$ & \\
\hline $\begin{array}{c}\text { Eye } \\
\text { LE }\end{array}$ & $13(0.48)$ & $13(0.46)$ & 0.8983 \\
RE & $14(0.52)$ & $15(0.54)$ & \\
\hline
\end{tabular}

F; female, LE; left eye, M; male, RE; right eye, TA; Triamcinolone acetonide group, TA-LF; liposomal formulation containing $2 \mathrm{mg} / \mathrm{ml}$ of TA group.

of irritation or surface problems due to the study formulation until the end of the study (Figure 2).

On the other hand, as expected, there was a significant increase in postoperative CFT and TMV compared to preoperative values in both groups; however, only the TA-LF group showed a significant improvement in contrast sensitivity (baseline value; $1.087 \pm 0.339$ vs week $12 ; 1.266 \pm 0.147$ ) and visual acuity compared to preoperative measurements (baseline value; $0.252 \pm$ 0.248 vs week $12 ; 0.005 \pm 0.136$ ). Table 3 summarizes the analysis of variables within groups.

Efficacy analysis between groups showed that patients treated with TA-LF had the lowest postoperative macular thickness and the best BCVA and contrast sensitivity after correction for baseline measurements (Table 4); however, these findings were non-statistically different compared to the TA group. There were no statistically significant differences in TMV and IOP between the TA and TA-LF groups in any case. Differences 


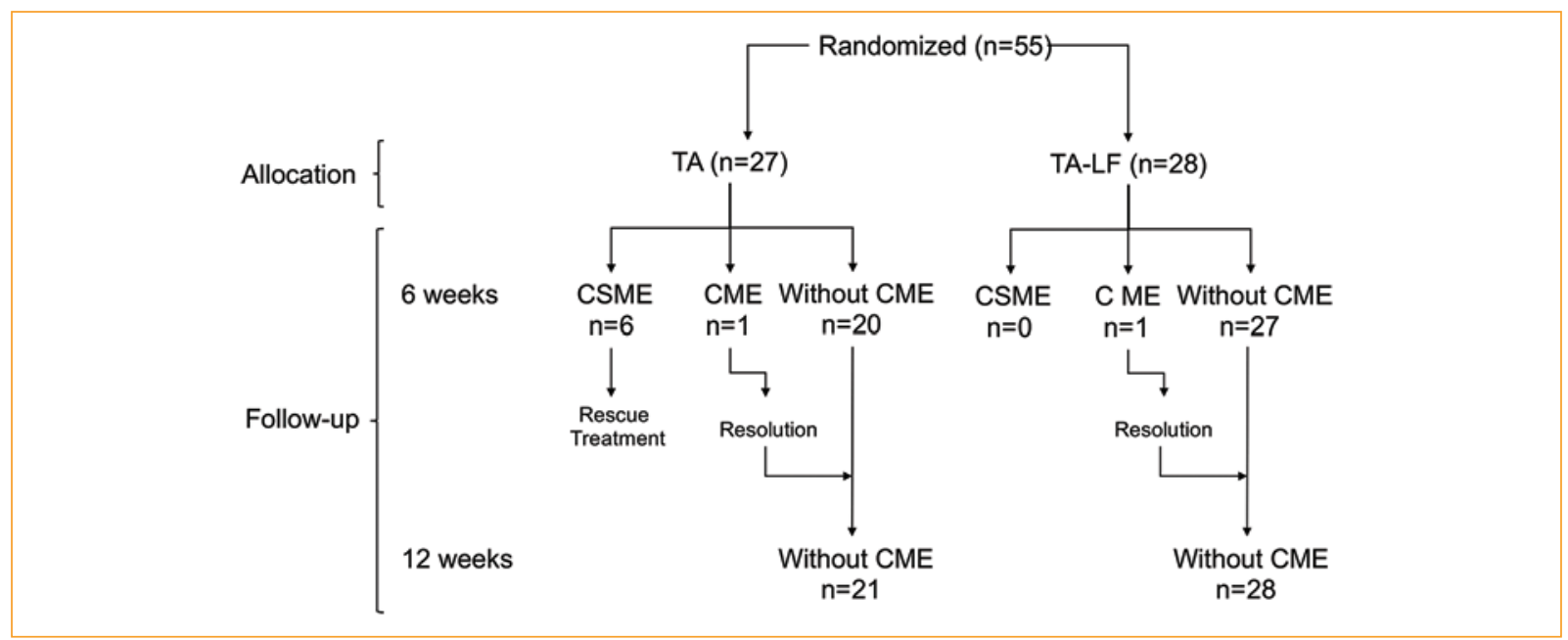

Figure 1. Flow diagram showing the number of eyes randomized and analyzed. CME; cystoid macular edema, CSME; clinically significant macular edema, TA; Triamcinolone acetonide group, TA-LF; liposomal formulation containing $2 \mathrm{mg} / \mathrm{ml}$ of TA group.

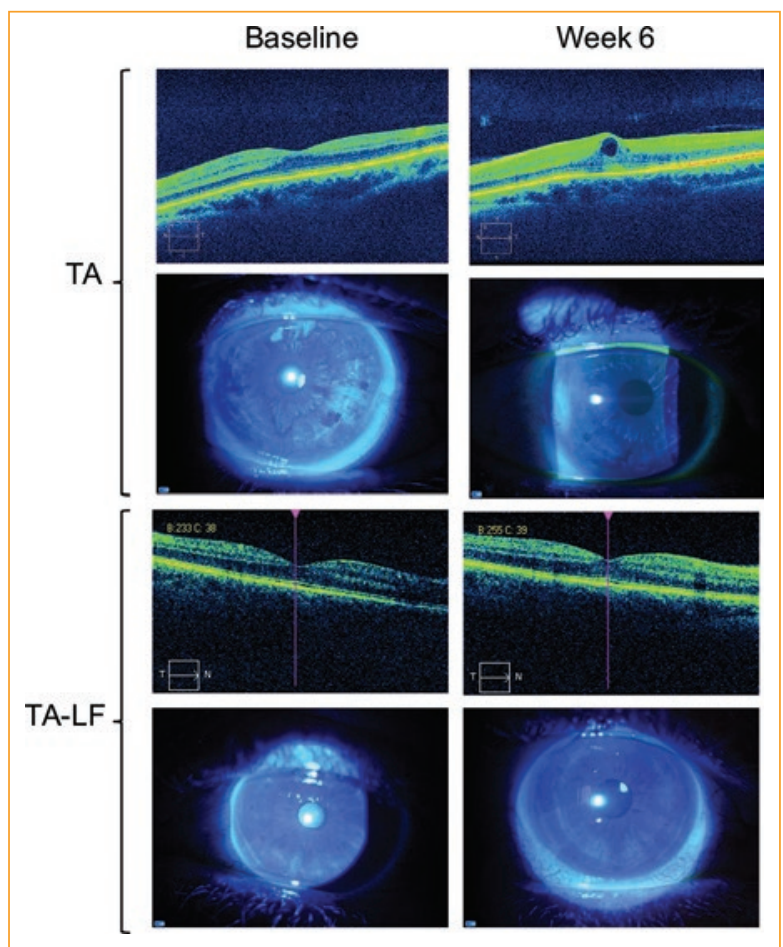

Figure 2. Representative cases. Baseline and postoperative images of fluorescein staining and OCT images in the TA and TA-LF groups. The tomographic images in the TA group correspond to one of the six cases with CSME, whereas the tomographic images in the TA-LF group correspond to the only case of CME. As we show in the photographs, no ocular surface adverse events were observed by fluorescein staining at 6 weeks of follow-up in any group. CME; cystoid macular edema, CSME; clinically significant macular edema, OCT; optical coherence tomography, TA; Triamcinolone acetonide group, TALF; liposomal formulation containing $2 \mathrm{mg} / \mathrm{ml}$ of TA group. between groups in visual acuity, contrast sensitivity, macular thickness, total macular volume and IOP are summarized in table 4.

Remarkably, CFT and TMV correlate significantly with contrast sensitivity only in the TA-LF group. The $r^{2}$ for CFT and contrast sensitivity was $0.1675(P=0.0306)$, whereas the $r^{2}$ for TMV and contrast sensitivity was $0.1675(P=0.0055)$ (Table 5).

Finally, we found that TA-LF showed the best preventive action for CSME. The incidences of CME and CSME in the TA group at 6 weeks were $3.7 \%$ and $22.2 \%$ respectively, whereas the incidence in the TA-LF group were of $3.7 \%$ and $0 \%$ (Table 6 ). The odds of developing CSME were significantly higher in the TA group than in the TA-LF group (OR, 9.44; 95\% Cl, 1.76 -50.66; $P=0.027$ ). All patients with CSME in the TA group required rescue treatment. The incidence of CME remained unchanged in the TA and TA-LF groups during the study, and it was not statistically significant at all time points (Table 6). OCT images of a representative case of CSME from the TA group and OCT images of the only case of CME in the TA-LF group are presented in Figure 2.

\section{Discussion}

PCME remains the most frequent postoperative complication that results in impaired vision after cataract surgery. Although mostly self-limited ${ }^{40}$, persistent and refractory cases represent a therapeutic challenge ${ }^{13}$. A wide range of pharmacologic agents have been used 
Table 3. Differences within groups in visual acuity, contrast sensitivity, macular thickness and total macular volume

\begin{tabular}{|c|c|c|c|c|c|}
\hline & & Baseline & $6 w$ & $12 w$ & P-value \\
\hline \multirow[t]{2}{*}{ Visual acuity (logMar) } & TA & $0.054 \pm 0.148$ & $0.072 \pm 0.189$ & $0.077 \pm 0.195$ & 0.9779 \\
\hline & TA-LF & $0.252 \pm 0.248$ & $0.03 \pm 0.142$ & $0.005 \pm 0.136$ & $<0.0001$ \\
\hline \multirow[t]{2}{*}{ Contrast sensitivity ( $1 /$ contrast) } & TA & $1.214 \pm 0.219$ & $1.194 \pm 0.173$ & $1.229 \pm 0.178$ & 0.513 \\
\hline & TA-LF & $1.087 \pm 0.339$ & $1.217 \pm 0.191$ & $1.266 \pm 0.147$ & 0.0346 \\
\hline \multirow[t]{2}{*}{ CFT (mm) } & TA & $258.33 \pm 32.50$ & $275.37 \pm 43.22$ & $275.38 \pm 47.26$ & 0.0143 \\
\hline & TA-LF & $256.21 \pm 15.16$ & $266.42 \pm 16.06$ & $265.92 \pm 18.55$ & $<0.0001$ \\
\hline \multirow[t]{2}{*}{ TMV $\left(\mathrm{mm}^{3}\right)$} & TA & $10.14 \pm 0.70$ & $10.41 \pm 0.58$ & $10.52 \pm 0.69$ & 0.031 \\
\hline & TA-LF & $10.08 \pm 0.71$ & $10.55 \pm 0.52$ & $10.50 \pm 0.52$ & $<0.0001$ \\
\hline \multirow[t]{2}{*}{ IOP $(\mathrm{mmHg})$} & TA & $15.11 \pm 3.25$ & $12.88 \pm 3.02$ & $13.52 \pm 2.50$ & 0.0193 \\
\hline & TA-LF & $15.71 \pm 2.20$ & $12.89 \pm 2.69$ & $13.50 \pm 1.93$ & 0.0193 \\
\hline
\end{tabular}

CFT; central foveal thickness, IOP; intraocular pressure, logMar: logarithm of the minimal angle of resolution; TA; Triamcinolone acetonide group, TA-LF; liposomal formulation containing $2 \mathrm{mg} / \mathrm{ml}$ of TA group, TMV; total macular volume, w; week.

Table 4. Differences between groups in visual acuity, contrast sensitivity, macular thickness and total macular volume

\begin{tabular}{|c|c|c|c|c|}
\hline & Parameter & TA & TA-LF & P-value \\
\hline \multirow[t]{3}{*}{ Visual acuity (logMar) } & Baseline & $0.054 \pm 0.148$ & $0.252 \pm 0.248$ & 0.000791 \\
\hline & $6 w$ & $0.072 \pm 0.189$ & $0.03 \pm 0.142$ & 0.349688 \\
\hline & $12 w$ & $0.077 \pm 0.195$ & $0.005 \pm 0.136$ & 0.135063 \\
\hline \multirow[t]{3}{*}{ Contrast sensitivity ( $1 /$ contrast) } & Baseline & $1.214 \pm 0.219$ & $1.087 \pm 0.339$ & 0.105633 \\
\hline & $6 w$ & $1.194 \pm 0.173$ & $1.217 \pm 0.191$ & 0.637007 \\
\hline & $12 w$ & $1.229 \pm 0.178$ & $1.266 \pm 0.147$ & 0.437292 \\
\hline \multirow[t]{3}{*}{ CFT $(\mu \mathrm{m})$} & Baseline & $258.333 \pm 32.504$ & $256.214 \pm 15.164$ & 0.756522 \\
\hline & $6 w$ & $275.37 \pm 43.229$ & $266.428 \pm 16.065$ & 0.310517 \\
\hline & $12 w$ & $275.38 \pm 47.267$ & $265.928 \pm 18.553$ & 0.338887 \\
\hline \multirow[t]{3}{*}{ TMV $\left(\mathrm{mm}^{3}\right)$} & Baseline & $10.14 \pm 0.707$ & $10.085 \pm 0.711$ & 0.774737 \\
\hline & $6 w$ & $10.414 \pm 0.584$ & $10.557 \pm 0.52$ & 0.343936 \\
\hline & $12 w$ & $10.52 \pm 0.697$ & $10.503 \pm 0.52$ & 0.886292 \\
\hline \multirow[t]{3}{*}{ IOP (mmHg) } & Baseline & $15.11 \pm 3.25$ & $15.71 \pm 2.2$ & 0.424754 \\
\hline & $6 w$ & $12.88 \pm 3.02$ & $12.89 \pm 2.69$ & 0.989694 \\
\hline & $12 w$ & $13.52 \pm 2.5$ & $13.5 \pm 1.93$ & 0.974905 \\
\hline
\end{tabular}

CFT; central foveal thickness, IOP; intraocular pressure, logMar: logarithm of the minimal angle of resolution; TA; Triamcinolone acetonide group, TA-LF; liposomal formulation containing $2 \mathrm{mg} / \mathrm{ml}$ of TA group, TMV; total macular volume, w; week.

for PCME treatment, including steroids $29,41,42$ and NSAIDs ${ }^{43-45}$. Corticosteroids are potent antiangiogenic and anti-inflammatory molecules that play a major role in the management of different vitreoretinal diseases due to its ability to regulate the expression of key genes such as VEGF and Interleukin-646,47. However, topical 
Table 5. Correlation between CFT and TMV with visual acuity and contrast sensitivity in TA and TA-LF groups

\begin{tabular}{|l|c|c|c|c|c|}
\hline & & \multicolumn{3}{|c|}{ Visual acuity (logMar) } & \multicolumn{2}{c|}{$\begin{array}{c}\text { Contrast sensitivity } \\
\text { (1/contrast) }\end{array}$} \\
\hline \multirow{2}{*}{ TA } & CFT & 0.04249 & 0.3023 & 0.01382 & 0.854 \\
\hline & TMV & 0.00008 & 0.9629 & 0.01236 & 0.5809 \\
\hline TA-LF & CFT & 0.1036 & 0.0948 & 0.1675 & 0.0306 \\
\hline & TMV & 0.06301 & 0.1976 & 0.2605 & 0.0055 \\
\hline
\end{tabular}

CFT; central foveal thickness, logMar: logarithm of the minimal angle of resolution; TA; Triamcinolone acetonide group, TA-LF; liposomal formulation containing $2 \mathrm{mg} / \mathrm{m}$ of TA group, TMV; total macular volume, w; week.

corticosteroids barely reach the posterior ocular segment due to both ocular and blood-retinal barriers. On the other hand, intravitreal injections of steroids reach suitable intraocular concentrations avoiding the ocular barriers $^{26}$. Intravitreal TA has shown to be suitable for refractory PCME treatment as well as other vitreoretinal diseases ${ }^{27-30,48-50}$. Nevertheless, to decrease ocular risks related to intravitreal TA injections and to preserve the benefits of using them in refractory PCME, it is necessary to develop alternative strategies for drug delivery.

A recent pharmacokinetic study of a novel topical triamcinolone acetonide-loaded liposomes formulation (TA-LF) reported that this formulation is capable of release TA efficiently in the vitreous and retina ${ }^{37}$. Also, a recent clinical study in patients with refractory PCME showed that TA-LF is effective in reducing CFT and improving BCVA in patients with this condition was well tolerated with an adequate safety profile and with no observed ocular adverse events or significant IOP changes $^{38}$. These findings suggest that topical TA-LF could be effective in the treatment of patients with refractory PCME and has the potential to substitute intravitreal steroids. This background prompted us to prove the efficacy of TA-LF in preventing PCME in this clinical assay. As shown, TA-LF had the best preventive action for CSME after FLACS when this formulation is compared to a conventional topical steroid formulation (TA $0.1 \%)$. The incidence of CSME in the TA group at 6 weeks was $22.2 \%$, whereas the incidence in the TA-LF group was $0 \%$. As it can be noted, the incidence of CSME in the TA group is perceptibly higher compared to the incidence in the TA-LF group. We presume that this phenomenon is related to the increased ability of TA-LF to reach the vitreous and retina and release TA in therapeutic doses. This assumption is based on the equivalence of the TA groups before and after FLACS. Also, the incidence of CSME after FLACS (22.2\%) differs greatly compared to the previous CSME $(0.8 \%)$ incidence reported by Ewe SY, et $\mathrm{al}^{9}$. It is possible that the higher incidence observed in our series is due to the operational definition of CSME used in our study ${ }^{25}$. Ewe SY, et al, defined CSME as an unexpected poor visual acuity (i.e., failure to improve postoperatively) or deteriorating visual acuity (compared to previous visits), either at the 3 to 4-week examination or at any subsequent visit, with evidence of cystoid macular edema by fundoscopy, spectral domain-optical coherence tomography (SD-OCT), or fluorescein angiography ${ }^{9}$. On the other hand, we used the definition of CSME proposed in the European multicenter trial of the prevention of cystoid macular edema after cataract surgery in nondiabetics (ESCRS PREMED). This trial is a large multicentric study of great impact to evaluate the preventive action of NSAIDs and steroids as monotherapy or combined therapy for $\mathrm{PCME}^{25}$. In this work, the definition of CSME was macular edema (increase in central subfield mean macular thickness of $10 \%$ or more compared to baseline, with cystic changes on SD-OCT), with less than a 0.2 logMAR BCVA improvement compared to the preoperative baseline ${ }^{25}$.

Moreover, the use of the conventional steroid formulation increased the risk of CSME with an OR of 9.44 $(95 \% \mathrm{Cl}, 1.76-50.66 ; \mathrm{P}=0.027)$ when this solution was compared with the novel TA-LF. These results suggest that the TA-LF surpasses the therapeutic activity of the conventional topical steroid formulation. Interestingly, IOP increase, a common adverse effect of topical steroids, was not observed in any group treated with conventional topical steroid formulation or the liposomal steroid formulation. Perhaps the time of use of the drug was relatively short (15 days) to induce this undesired effect. In fact, IOP significantly decreased after cataract surgery. This phenomenon was not unexpected, because it is well known that cataract surgery reduces intraocular pressure around 1.5 to $4 \mathrm{mmHg}^{51}$. The mechanism of this effect is not clear, but it seems related to anatomical and physiological changes induced by lens surgery ${ }^{52}$.

Compared with previous studies using other topical steroids, TA-LF remains therapeutically superior. For example, a retrospective study comparing topical steroids for PCME prevention (defined as new or worsening anatomic macular edema or thickening demonstrated by $\mathrm{OCT}$ ), reported a non-significant difference in the rate of postoperative $\mathrm{CME}$ in patients receiving 
Table 6. Incidence of CME and CSME and Odds Ratio values

\begin{tabular}{|c|c|c|c|c|}
\hline \multirow[t]{2}{*}{ Parameter } & TA & TA-LF & \multirow[t]{2}{*}{ OR $(95 \%$ CI)* } & \multirow[t]{2}{*}{$P$ value } \\
\hline & Incidence $\mathrm{n} / \mathrm{N}(\%)$ & Incidence $n / N(\%)$ & & \\
\hline CME within $6 \mathrm{w}$ & $1 / 27(3.7)$ & $1 / 28(3.5)$ & $1.038(0.0617-17.48)$ & 0.97 \\
\hline CME within $12 \mathrm{w}$ & $1 / 21(4.7)$ & $1 / 28(3.5)$ & $1.33(0.078-22.57)$ & 0.84 \\
\hline CSME within 6 w & $6 / 27(22.2)$ & $0 / 28(0)$ & $9.44(1.76-50.66)$ & 0.027 \\
\hline CSME within $12 \mathrm{w}$ & $0 / 21(0)$ & $0 / 28(0)$ & $1.325(0.025-69.52)$ & 0.88 \\
\hline
\end{tabular}

Cl; confidence interval, CME; cystoid macular edema, CSME; clinically significant macular edema, OR; Odds Ratio, TA; Triamcinolone acetonide group, TA-LF; liposomal formulation containing $2 \mathrm{mg} / \mathrm{ml}$ of TA group. Odds of developing CME and CSME in the TA group are presented.

prednisolone acetate $1 \%$ and dexamethasone sodium phosphate $0.1 \%(4.0 \% \text { vs } 4.1 \%, P=0.94)^{22}$, whereas in a large prospective study, the incidence of CSME was of $5.1 \%$ for dexamethasone sodium phosphate $0.1 \%$. In any case, the incidence of cystoid macular edema is lower than with $\mathrm{TA}-\mathrm{LF}^{25}$, presumably because of the use of liposomes.

Liposome-based eye drops have been proposed as a new drug delivery system for the posterior segment of the eye, with the potential to deliver drugs at therapeutic concentrations to the vitreous cavity and retina ${ }^{37}$. Liposomes (LPs) are particles composed of an aqueous core delimited by a membrane-like lipid bilayer that acts as a carrier for water-soluble, lipid-soluble and amphiphilic drugs ${ }^{53-56}$. LPs are non-toxic, lowly antigenic, easily metabolized and biodegradable ${ }^{57}$, and they have been used to improve drug transport and bioavailability in ocular tissues ${ }^{58,59}$. The findings of this study support the liposomes potential to increase the bioavailability (based in its superior therapeutic efficiency), as well as their safety, since none of the patients showed signs of irritation or surface problems, or significant IOP increases secondary to the study formulation. However, complementary studies need to be performed to confirm these findings.

Interestingly, patients treated with TA-LF had the lowest postoperative macular thickness and the best BCVA and contrast sensitivity after correction for baseline measurements (Table 3); however, these findings were not statistically significant compared with the TA group. It is possible that in further studies with larger sample sizes, significant differences could be achieved. This possibility is of great interest for modern lens surgery, especially in lens surgery for presbyopia, where the main goal is visual quality.

Finally, there are several limitations to our study. First, the lack of a control group is a major concern, but due to ethical considerations, a placebo group was not considered. The second major limitation of our study is the small sample size.

In conclusion, the TA-loaded liposomal formulation is effective for the prevention of CSME associated with FLACS, and it seems that its therapeutic activity could be superior to the activity of conventional topical steroid formulations. However, further studies should be considered.

\section{Conflicts of interest}

The authors declare no conflicts of interest.

\section{Ethical disclosures}

Protection of human and animal subjects. The authors declare that the procedures followed were in accordance with the regulations of the relevant clinical research ethics committee and with those of the Code of Ethics of the World Medical Association (Declaration of Helsinki).

Confidentiality of data. The authors declare that they have followed the protocols of their work center on the publication of patient data.

Right to privacy and informed consent. The authors have obtained the written informed consent of the patients or subjects mentioned in the article. The corresponding author is in possession of this document.

\section{References}

1. Bourne RR, Stevens GA, White RA, et al. Causes of vision loss worldwide, 1990-2010: a systematic analysis. Lancet Glob Health 2013;1: e339-349.

2. Sight. WHOVTRt. Global Initiative for the Elimination of Avoidable Blindness; Action Plan 2006-2011. In: WHO (ed), http://appswhoint/iris/bitstr eam/10665/43754/1/9789241595889_engpdf. Geneva, Switzerland: WHO; 2007.

3. Ang RET, Quinto MMS, Cruz EM, et al. Comparison of clinical outcomes between femtosecond laser-assisted versus conventional phacoemulsification. Eye Vis (Lond) 2018:5:8.

4. Chu CJ, Johnston RL, Buscombe C, et al. Risk Factors and Incidence of Macular Edema after Cataract Surgery: A Database Study of 81984 Eyes. Ophthalmology 2016;123:316-323. 
5. Perente I, Utine CA, Ozturker C et al. Evaluation of macular changes after uncomplicated phacoemulsification surgery by optical coherence tomography. Curr Eye Res 2007;32:241-247.

6. Ecsedy M, Mihaltz K, Kovacs I, et al. Effect of femtosecond laser cataract surgery on the macula. J Refract Surg 2011;27:717-722.

7. Nagy ZZ, Ecsedy M, Kovacs I, et al. Macular morphology assessed by optical coherence tomography image segmentation after femtosecond laser-assisted and standard cataract surgery. J Cataract Refract Surg 2012;38:941-946.

8. Abell RG, Allen PL, Vote BJ. Anterior chamber flare after femtosecond laser-assisted cataract surgery. J Cataract Refract Surg 2013:39:1321-1326.

9. Ewe SY, Oakley CL, Abell RG, et al. Cystoid macular edema after femtosecond laser-assisted versus phacoemulsification cataract surgery. $J$ Cataract Refract Surg 2015;41:2373-2378.

10. Henderson BA, Kim JY, Ament CS, et al. Clinical pseudophakic cystoid macular edema. Risk factors for development and duration after treatment. J Cataract Refract Surg 2007;33:1550-1558.

11. Zur D, Loewenstein A. Postsurgical Cystoid Macular Edema. Dev Ophthalmol 2017;58:178-190.

12. Coscas G, Cunha-Vaz J, Soubrane G. Macular Edema: Definition and Basic Concepts. Dev Ophthalmol 2017:58:1-10.

13. Schmier JK, Halpern MT, Covert DW, Matthews GP. Evaluation of costs for cystoid macular edema among patients after cataract surgery. Retina 2007;27:621-628

14. Belair ML, Kim SJ, Thorne JE, et al. Incidence of cystoid macular edema after cataract surgery in patients with and without uveitis using optical coherence tomography. Am J Ophthalmol 2009;148:128-135 e122.

15. Yeh PC, Ramanathan S. Latanoprost and clinically significant cystoid macular edema after uneventful phacoemulsification with intraocular lens implantation. J Cataract Refract Surg 2002;28:1814-1818.

16. Panteleontidis V, Detorakis ET, Pallikaris IG, Tsilimbaris MK. Latanoprost-Dependent Cystoid Macular Edema Following Uncomplicated Cataract Surgery in Pseudoexfoliative Eyes. Ophthalmic Surg Lasers Imaging 2010;1-5.

17. Rossetti L, Autelitano A. Cystoid macular edema following cataract surgery. Curr Opin Ophthalmol 2000;11:65-72.

18. Nikica G, Ljerka HP, Jelena $P$, et al. Cystoid macular edema in anterior chamber lens implantation following posterior capsule rupture. Doc Ophthalmol 1992:81:309-315.

19. Ah-Fat FG, Sharma MK, Majid MA, Yang YC. Vitreous loss during conversion from conventional extracapsular cataract extraction to phacoemulsification. J Cataract Refract Surg 1998:24:801-805.

20. Chinchurreta Capote AM, Lorenzo Soto M, Rivas Ruiz F, et al. Comparative study of the efficacy and safety of bromfenac, nepafenac and diclofenac sodium for the prevention of cystoid macular edema after phacoemulsification. Int J Ophthalmol 2018;11:1210-1216.

21. El Gharbawy SA, Darwish EA, Abu Eleinen KG, Osman MH. Efficacy of addition of nepafenac $0.1 \%$ to steroid eye drops in prevention of post-phaco macular edema in high-risk eyes. Eur $J$ Ophthalmol 2018;1120672118799626

22. Baartman BJ, Gans R, Goshe J. Prednisolone versus dexamethasone for prevention of pseudophakic cystoid macular edema. Can J Ophthalmol 2018:53:131-134

23. Ylinen P, Holmstrom E, Laine I, et al. Anti-inflammatory medication following cataract surgery: a randomized trial between preservative-free dexamethasone, diclofenac and their combination. Acta Ophthalmol 2018;96:486-493

24. Guo S, Patel S, Baumrind B, et al. Management of pseudophakic cystoid macular edema. Surv Ophthalmol 2015;60:123-137.

25. Wielders LHP, Schouten J, Winkens B, et al. European multicenter tria of the prevention of cystoid macular edema after cataract surgery in nondiabetics: ESCRS PREMED study report 1. J Cataract Refract Surg 2018:44:429-439

26. Feigenbaum A, Kornbluth W. Intravitreal injection of penicillin in a case of incipient abscess of the vitreous following extracapsular cataract extraction; perfect cure. Ophthalmologica 1945;110:300-305

27. Conway MD, Canakis C, Livir-Rallatos C, Peyman GA. Intravitreal triamcinolone acetonide for refractory chronic pseudophakic cystoid macular edema. J Cataract Refract Surg 2003;29:27-33.

28. Benhamou N, Massin P, Haouchine B, et al. Intravitreal triamcinolone for refractory pseudophakic macular edema. Am J Ophthalmol 2003;135:246-249.

29. Boscia F, Furino C, Dammacco R, et al. Intravitreal triamcinolone acetonide in refractory pseudophakic cystoid macular edema: functional and anatomic results. Eur J Ophthalmol 2005;15:89-95.

30. Koutsandrea C, Moschos MM, Brouzas D, et al. Intraocular triamcinolone acetonide for pseudophakic cystoid macular edema: optical coherence tomography and multifocal electroretinography study. Retina 2007:27:159-164.

31. Lyall DA, Tey A, Foot B, et al. Post-intravitreal anti-VEGF endophthalmitis in the United Kingdom: incidence, features, risk factors, and outcomes. Eye (Lond) 2012;26:1517-1526.

32. Poku E, Rathbone J, Wong R, et al. The safety of intravitreal bevacizumab monotherapy in adult ophthalmic conditions: systematic review. BMJ Open 2014; 4:e005244.
33. Fung AE, Rosenfeld PJ, Reichel E. The International Intravitreal Bevacizumab Safety Survey: using the internet to assess drug safety worldwide. Br J Ophthalmol 2006;90:1344-1349.

34. Arikan G, Osman Saatci A, Hakan Oner F. Immediate intraocular pressure rise after intravitreal injection of ranibizumab and two doses of triamcinolone acetonide. Int J Ophthalmol 2011;4:402-405.

35. Chan CK, Fan DS, Chan WM, et al. Ocular-hypertensive response and corneal endothelial changes after intravitreal triamcinolone injections in Chinese subjects: a 6-month follow-up study. Eye (Lond) 2005;19: 625-630.

36. Veritti D, Di Giulio A, Sarao V, Lanzetta P. Drug safety evaluation of intravitreal triamcinolone acetonide. Expert Opin Drug Saf 2012;11:331-340.

37. Altamirano-Vallejo JC, Navarro-Partida J, Gonzalez-De la Rosa A, et al. Characterization and Pharmacokinetics of Triamcinolone Acetonide-Loaded Liposomes Topical Formulations for Vitreoretinal Drug Delivery. J Ocul Pharmacol Ther 2018;34:416-425.

38. Gonzalez-De la Rosa A, Navarro-Partida J, Altamirano-Vallejo JC, et al. Novel Triamcinolone Acetonide-Loaded Liposomes Topical Formulation for the Treatment of Cystoid Macular Edema After Cataract Surgery: A Pilot Study. J Ocul Pharmacol Ther 2019

39. Gonzalez-De la Rosa A, Navarro-Partida J, Altamirano-Vallejo JC, et al. Novel Triamcinolone Acetonide-Loaded Liposomal Topical Formulation Improves Contrast Sensitivity Outcome After Femtosecond Laser-Assisted Cataract Surgery. J Ocul Pharmacol Ther 2019.

40. Levin DS, Lim JI. Update on pseudophakic cystoid macular edema treatment options. Ophthalmol Clin North Am 2002;15:467-472.

41. Heier JS, Topping TM, Baumann W, et al. Ketorolac versus prednisolone versus combination therapy in the treatment of acute pseudophakic cystoid macular edema. Ophthalmology 2000;107:2034-2038;discussion 2039.

42. Meyer LM, Schonfeld CL. Cystoid Macular Edema after Complicated Cataract Surgery Resolved by an Intravitreal Dexamethasone 0.7-mg Implant. Case Rep Ophthalmol 2011;2:319-322.

43. Rho DS. Treatment of acute pseudophakic cystoid macular edema: Diclofenac versus ketorolac. J Cataract Refract Surg 2003;29:2378-2384.

44. Warren KA, Fox JE. Topical nepafenac as an alternate treatment for cystoid macular edema in steroid responsive patients. Retina 2008;28:1427-1434

45. Warren KA, Bahrani H, Fox JE. NSAIDs in combination therapy for the treatment of chronic pseudophakic cystoid macular edema. Retina 2010;30:260-266.

46. Zhang X, Wang N, Schachat AP, et al. Glucocorticoids: structure, signaling and molecular mechanisms in the treatment of diabetic retinopathy and diabetic macular edema. Curr Mol Med 2014;14:376-384.

47. Ebrahem Q, Minamoto A, Hoppe G, et al. Triamcinolone acetonide inhibits IL-6- and VEGF-induced angiogenesis downstream of the IL-6 and VEGF receptors. Invest Ophthalmol Vis Sci 2006;47:4935-4941.

48. Kwon SI, Kim YW, Bang YW, et al. Comparison of natural course, intravitreal triamcinolone, and intravitreal bevacizumab for treatment of macular edema secondary to branch retinal vein occlusion. J Ocul Pharmacol Ther 2013;29:5-9.

49. Habot-Wilner Z, Sallam A, Pacheco PA, et al. Intravitreal triamcinolone acetonide as adjunctive treatment with systemic therapy for uveitic macular edema. Eur J Ophthalmol 2011;21 Suppl 6:S56-61.

50. Yalcinbayir O, Gelisken O, Kaderli B, Avci R. Intravitreal versus sub-tenon posterior triamcinolone injection in bilateral diffuse diabetic macular edema. Ophthalmologica 2011;225:222-227.

51. Shrivastava A, Singh K. The effect of cataract extraction on intraocular pressure. Curr Opin Ophthalmol 2010;21:118-122.

52. Slabaugh MA, Chen PP. The effect of cataract extraction on intraocular pressure. Curr Opin Ophthalmol 2014;25:122-126.

53. Klibanov AL, Maruyama K, Torchilin VP, Huang L. Amphipathic polyethyleneglycols effectively prolong the circulation time of liposomes. FEBS Lett 1990;268:235-237.

54. Lopez-Berestein G, Mehta R, Hopfer R, et al. Effects of sterols on the therapeutic efficacy of liposomal amphotericin B in murine candidiasis. Cancer Drug Deliv 1983:1:37-42.

55. Oku N, Nojima S, Inoue K. Selective release of non-electrolytes from liposomes upon perturbation of bilayers by temperature change or polyene antibiotics. Biochim Biophys Acta 1980;595:277-290.

56. Allen TM, Cullis PR. Drug delivery systems: entering the mainstream. Science 2004;303:1818-1822.

57. van Rooijen N, van Nieuwmegen R. Liposomes in immunology: multilamellar phosphatidylcholine liposomes as a simple, biodegradable and harmless adjuvant without any immunogenic activity of its own. Immunol Commun 1980;9:243-256.

58. Di Tommaso C, Bourges JL, Valamanesh F, et al. Novel micelle carriers for cyclosporin A topical ocular delivery: in vivo cornea penetration, ocular distribution and efficacy studies. Eur J Pharm Biopharm 2012; 81:257-264.

59. Hathout RM, Mansour S, Mortada ND, Guinedi AS. Liposomes as an ocular delivery system for acetazolamide: in vitro and in vivo studies. AAPS PharmSciTech 2007:8:1. 